\title{
DOE/ER/6196\%-TI
}

\section{Development of a SWIR Solar Spectral Radiometer for the ARM Program}

Final Report on Grant DE-FG03-95ER61964

by

Frank Murcray

Department of Physics and Astronomy

University of Denver

September, 1998

Distribution of THS DOCHENT is UNLMTED 


\section{DISCLAIMER}

This report was prepared as an account of work sponsored by an agency of the United States Government. Neither the United States Government nor any agency thereof, nor any of their employees, makes any warranty, express or implied, or assumes any legal liability or responsibility for the accuracy, completeness, or usefulness of any information, apparatus, product, or process disclosed, or represents that its use would not infringe privately owned rights. Reference herein to any specific commercial product, process, or service by trade name, trademark, manufacturer, or otherwise does not necessarily constitute or imply its endorsement, recommendation, or favoring by the United States Government or any agency thereof. The views and opinions of atuthors expressed herein do not necessarily state or reflect those of the United States Government or any agency thereof. 


\section{DISCLAIMER}

Portions of this document may be illegible in electronic image products. Images are produced from the best available original document. 


\section{Introduction}

The goal of this grant was to develop an absolutely calibrated spectral radiometer covering the 1 to $5 \mu \mathrm{m}$ spectral region for the DOE ARM (Atmospheric Radiation Measurements) program. This instrument is called the Absolute Solar Transmittance Interferometer (ASTI). This effort was based on earlier results from grant DE-FG02-92ER61360.

The instrument is based on a small, commerically available interferometer, built by Bomem, Inc., of Quebec, Canada. For the earlier grant, we constructed a breadboard version of ASTI, which was used to study the linearity, zero offset, gain stability, etc. These all indicated that an instrument of this type could achieve precison of $1 \%$ or better, with accuracy limited by the calibration standards (nominally $3 \%$ ). For this grant, we constructed a prototype instrumer.t for possible use at the ARM sites.

\section{Instrument Construction}

For the prototype ASTI we again used a Bomem MB102 spectrometer, with a $\mathrm{ZnSe}$ beamsplitter which permits operation from 0.7 to $18 \mu \mathrm{m}$. A single InSb detector is used, with 3 computer selectable bandpass filters which divide the 1 to $5 \mu \mathrm{m}$ region into 3 more or less equal sections. The interferometer is mounted on a servo controlled rotation table, which maintains orientation toward the sun. A small, servo controlled elevation mirror directs sunlight into the interferometer. Interferograms are coadded for short periods, typically 2 minutes per filter.

The instrument had no measureable zero offset. This allows a single point calibration (at each wavelength). The calibration source chosen was a tungsten filament lamp, calibrated by Optronics Laboratorys for spectral radiance between 0.5 and $6 \mu \mathrm{m}$. Viewing the calibration source uses the identical optics as viewing the sun. The measured solar intensity is simply the observed signal times the known lamp intensity divided by the lamp signal, carried out wavelength by wavelength.

\section{Optical Design}

In principle, the best calibration method is to use exactly the same optical system to view the calibration source and the sun. The sun is far away, but subtends about $1 / 2^{\circ}$. The calibration lamp is 2 by $7 \mathrm{~mm}$, with the calibration effective for the central 1.4 by $5 \mathrm{~mm}$. In order to steer the solar beam into the interferometer, a mirror mounted at $45^{\circ}$ to the 
optical axis is used for elevation, and the entire interferometer is oriented in azimuth. When direct horizontally, the elevation mirror is used to view the calibration lamp.

To minimize the effects of solar limb darkening, it was decided to use only the central $1 / 4^{\circ}$ of the solar disk. A circular aperture is used to determine the angular acceptance angle of the detector. The $14^{\circ}$ is significantly smaller than the angular size of the central fringe, $1.1^{\circ}$, at the maximum frequency and path difference $(1 \mathrm{~cm})$.

The lamp filament must be imaged by the optical system. In this case, a 1:1 real image was desired. The physical dimensions of the interferometer and tracking mirror required that the lamp be at least $1 / 2 \mathrm{~m}$ in front of the interferometer, with the internal path using another $1 / 2 \mathrm{~m}$. Thus, a $1 / 2 \mathrm{~m}$ focal length spherical mirror is used, with the lamp $1 \mathrm{~m}$ in front of the mirror, and the real image $1 \mathrm{~m}$ behind. A circular aperture at the focus of this mirror provides the angular field of view limit. The interferometer has $25 \mathrm{~mm}$ diameter optics, and the small divergence of the beam allows ample room the 1.4 by $5 \mathrm{~mm}$ slot. The circular aperture is reimaged onto the detector, using another spherical mirror with $4: 1$ demagnification to match the detector size to the physical aperture size. A flat folding mirror is used to minimize the size of the optical table. Both spherical mirrors are operated slightly off axis, but ray tracing showed minimal aberation effects, and both sources are oversized.

\section{Electronic Design}

The basic interferometer includes an A/D converter and all necessary sampling electronics, along with computer interfaces. The InSb detector is photovoltaic, producing a current that is proportional to the incident intensity. This current is converted to a voltage a by a quality FET input operaticnal amplifier operated as a transimpedance amplifier. The amplifier has two different gain settings to accomodate the intensity range of up to 100 between the sun and the standard lamp. The gain is measured by observing the calibration lamp with both settings.

The linearity of the detector/electronics combination is of primary concern, since we are using a single point calibration where the answer is really an extrapolation. Linearity can be verified in each interferogram, because the spectrum includes regions known to have zero intensity. Any linearity error causes a zero offset, which can be readily identified. Linearity is checked at $125 \%$ of the solar intensity by using a slightly larger circular aperture. 


\section{Solar Tracker}

The solar tracker consists of an azimuth platform, which holds the interferometer and a small elevation tracking mirror. The azimuth platform is turned by a large torque motor, which has feedback from an X-Y position sensor located on the elevation motor shaft. The elevation mirror is also controlled by the $\mathrm{X}-\mathrm{Y}$ position sensor. The center of the azimuth torque motor shaft is hollow, allowing electrical cables to feed from the platform to the computer below.

Except for wind loading, the tracker can correctly position the solar beam to within 2 arc-minutes. Under windy conditions, data collection has to be suspended.

\section{Data Processing}

Interferograms are collect by a personal computer, which also performs the fast Fourier Transform (FFT) to convert them into spectra. Spectra are collected with three different spectral bandpass filters. Calibration spectra are usually collected about midday, while the solar spectra are run from early morning to late afternoon to get maximum variation in atmospheric path. The calibration of the spectra is carried out after the completion of a days runs.

\section{Operation}

The ASTI prototype has been operated on several intensive operations periods at the DOE ARM site in central Oklahoma, in additon to days of testing in Denver and a week of data collection from Mt. Evans, Colorado. The first IOP was in April, with mild weather conditions, and the system worked very well. During a June IOP, the instrument overheated badly, and had to be shut down during the middle of the day. We had problems with cool temperatures on Mt. Evans. A small air-conditioner was purchased to provide a cool air flow from the bottom of the solar tracker up over the interferometer. This is sufficient to allow operation.

As part of the initial grant, we purchased a calibration lamp. For this grant, we purchase a second lamp, and returned the first for recalibration at the same time. The two lamps were calibrated seperately, but on the same day. When we began using the lamps we noticed that they were more thar. $3 \%$ different in some spectral regions. We feel this is the limiting factor for the overall accuracy of the measurement.

Although the ASTI has operated at the ARM site, we have been unable to automate the calibration procedure suffic ently for site personell to take over operation. For this 
reason, the development of the instrument stopped at the current, semi-automatic stage. Data from the IOPs have been provided to the ARM data center, and the instrument continues to be operated during some IOPs.

Overall, the development has been highly successful. The instrument accuracy limits appear to be of the order of $1 \%$, if we can overcome the limitations of the calibration sources. 